\title{
Effort investment in uncontrollable situations: The moderating role of motivation toward closure
}

\author{
Paulina Szwed $^{1}\left[\right.$ (D) Małgorzata Kossowska ${ }^{1} \cdot$ Marcin Bukowski $^{1}$
}

Accepted: 27 January 2021 / Published online: 11 February 2021

(c) The Author(s) 2021

\begin{abstract}
According to the principle of energy-conservation principle, effort investment is usually reduced in situations that are perceived as uncontrollable. This is because when success is recognized as impossible, any effortful actions are no longer justified. However, we predicted that individual differences in uncertainty tolerance, i.e., the need for closure (NFC), may moderate effort investment in uncontrollable situations. We tested this prediction in two experimental studies in which we exposed participants with differing levels of NFC to uncontrollable events, and indexed effort through the assessment of systolic blood pressure (SBP) responses. As predicted, in the uncontrollability (vs. controllability) condition, effort investment decreased significantly among low- but not high-NFC participants. Since gaining certainty and achieving closure is not a critical epistemic goal for low-NFC individuals, exerting extra effort to gain certainty is therefore no longer justified. On the other hand, high-NFC participants do not withhold their efforts, as they are highly motivated to obtain certainty. These results may help to account for contradictory findings in effort-investment behaviour and add substantively to the literature concerning motivation toward closure.
\end{abstract}

Keywords Uncontrollability $\cdot$ Need for closure $\cdot$ Goal-striving strategies $\cdot$ Effort mobilization $\cdot$ Systolic blood pressure

\section{Introduction}

For over four decades, the topic of the psychological consequences of facing an uncontrollable situation has attracted the attention of motivational, clinical, social, cognitive, and developmental psychologists (Bukowski and Kofta 2017; Langer and Roth 1975; Mikulincer 1994; Pittman and Pittman 1980; Seligman 1975; Skinner 1995; Weary et al. 1993). Being in control, by definition, is the possession of the actual or perceived ability to have an impact on present events, and the expectancy that the desired outcomes will be achieved, and undesired ones will be avoided (Burger 1989). Loss of control can be described as a highly aversive state which has acute consequences for human well-being and performance (Maier and Seligman 1976). Seligman (1975) showed that when faced with uncontrollability, organisms suffer from cognitive, affective, and motivational deficits. Lacking control was associated with passive, apathetic

Paulina Szwed

paulina.szwed@uj.edu.pl

1 Department of Philosophy, Institute of Psychology, Jagiellonian University, Ingardena 6, 30-060 Kraków, Poland responses but also with increased cognitive exhaustion, reduced attentional control, and reduced effort investment (e.g., Bukowski et al. 2015; Kofta and Sedek 1998; Lefcourt 1976, 1980). These findings are precisely in line with Brehm's Motivational Intensity Theory (MIT, Brehm and Self 1989; Wright 1996), which states that when faced with an unsolvable task that induces control deficits, an individual will disengage from further action. According to the energy conservation principle, this is because when success is perceived as impossible, any effortful actions are not justified (Brehm and Self 1989; see Gendolla and Wright 2005, for an overview). However, when uncertainty related to the possibility of success in a given task is high (e.g., due to unknown difficulty levels), then only the subjective importance of success should guide effort mobilization (Brehm and Self 1989; Wright 1996). Therefore, it seems justified to expect that chronic individual differences in epistemic motivation, which determines the subjective importance of reducing uncertainty, can modulate the amount of effort invested in a given task (Sankaran et al. 2017; Szumowska et al. 2017). In the current studies, we focus on the role of the motivation to reduce uncertainty when engaged in tasks whose solvability cannot be determined. 


\section{Facing unsolvable tasks: effort (de) mobilization}

Wright's integrative model of human engagement (1996), which is based on motivation intensity theory (MIT; Brehm and Self 1989; Wright 1996), predicts that in any performance situation, a change in effort mobilization (manifested in beta-adrenergic activity) should be observed that is proportional to task difficulty (e.g., the complexity of the task), as long as success is possible and worthwhile. Otherwise, when success is not possible and/ or not worthwhile, a decline in effort investment (subduing beta-adrenergic activation) is usually observed. This model has been positively verified on numerous occasions (Richter et al. 2016a, b). For example, Richter et al. (2008) showed that participants' systolic blood pressure (SBP) increased along with task difficulty up to the point at which the task was impossible to perform, at which point the participants' SBP decreased. However, in line with MIT, task demands determined effort mobilization directly, but also indirectly, since it is set by the level of potential motivation, i.e. the maximum level of effort one is willing to invest in the given task. Moreover, the theory also assumes that when task difficulty is unknown, the amount of invested effort will be determined solely by the potential motivation, i.e., one's motivation to succeed in a given performance situation, rather than by the objective difficulty of the task (e.g. Gendolla et al. 2012). Potential motivation can be driven by situational factors (i.e., the level of reward) but also by individual ones, such as chronic motives (e.g., the motives to be consistent, accurate, certain etc.). All of these factors should be considered when discussing coping responses to uncontrollability (Ford and Brehm 1987). Thus, we claim that, when the difficulty of the task is unknown (i.e., the possibility of succeeding is uncertain), the amount of effort invested in it should be guided by an individual's motivation to reduce uncertainty, rather that the objective performance settings. Thus, in our studies, we aim to investigate how individual differences in the tolerance of uncertainty modulates the level of one's potential motivation, and therefore can shape the effort investment in uncontrollable situations i.e., when the difficulty level is unknown.

\section{Motivation toward closure, uncontrollability, and effort investment}

Individual differences in tolerance of uncertainty can be understood in terms of the Need for Cognitive Closure construct (NFC, Kruglanski 1989). NFC refers to an individual's aversion towards uncertainty and the desire to rapidly reduce it when experienced. Individuals high in NFC desire firm, certainty-providing knowledge, whereas individuals low in NFC are open to prolonging uncertainty (Kruglanski 1989). Previous studies have shown that people with high NFC prefer effort-minimizing strategies in task performance situations (see Kruglanski and Webster 1996; Roets et al. 2015). However, other studies have revealed that they can invest more effort in task performance than their low-NFC counterparts when faced with ambiguous tasks or experimentally evoked uncertainty (Kossowska et al. 2018). This effort investment pattern of NFC has also been demonstrated in psychophysiological studies when the only instrumental option to restore certainty was effortful performance (effort indexed as SBP, Szumowska et al. 2017) or when a task was unsolvable, but important (effort measured at the neurocortical level, Kossowska et al. 2019). A similar pattern of results was found in research performed by Richter et al. (2012), who addressed a related problem. In the study of Richter et al., however, the focus was on the interaction of objective task difficulty and NFC on engagement-related myocardial beta-adrenergic activity. They found that high- (vs. low-) NFC participants, when faced with a difficult task (due to its complexity), showed increased PEP (pre-ejection period) reactivity, indicating higher levels of mental effort. Our research here aims at extending those findings by focusing on the NFC when the difficulty of the task is unknown, i.e., its solvability cannot be determined. Following Wright and Brehm (1984), who distinguished between uncertainty related to the objective difficulty of the task (for instance, its complexity) and uncertainty about how to exercise control over performance/outcome, we assume that the second kind of uncertainty is crucial in the context of un(controllability). So, in contrast to Richter et al. (2012), who focused on the first type of uncertainty (manipulating the objective difficulty of the task), we are more concerned with the second type, i.e., uncertainty about how to act in order to succeed in a given task (manipulated by the perceived solvability of the task, when the objective difficulty remains unknown). This type of behavioural uncertainty is a central state defining uncontrollability (Bukowski and Kofta 2017; Kofta and Sedek 1999).

In terms of MIT, we argue that differences in NFC (as an important chronic goal seeking to reduce uncertainty) should set the different levels of potential motivation in a task performance situation when the level of difficulty remains unknown (uncontrollability), and therefore, in turn, should guide the level of invested effort. In such circumstances, individuals high in NFC should have high potential motivation since gaining certainty is their focal goal. Therefore, when faced with uncontrollability, these individuals should 
prolong their effort investment. Conversely, for low-NFC individuals, gaining certainty is not an essential epistemic goal, therefore exerting effort to reduce uncertainty is not justified, i.e., the potential motivation of low-NFC individuals should be low in uncontrollable situations. In other words, these participants should disengage by withholding effort when faced with uncontrollable events (this assumption is presented in Fig. 1).

\section{Overview of the studies}

To test these predictions, we ran two experimental studies in which we assigned participants to uncontrollability vs. controllability conditions, and observed their effort investment patterns. Following the definition of effort as the mobilization of resources for action, we operationalized it via betaandrogenic activation as manifested in Systolic Blood Pressure (for an overview, see: Silvestrini and Gendolla 2019). In Study 1 , uncontrollability was induced using a computerized version of Behavioural Helplessness Training (BHT; Kofta and Sedek 1989), and in Study 2, we used Informational Helplessness Training (IHT; Sedek and Kofta 1990). In Study 1, during the BHT, the participants in the controllability condition were provided with feedback related to their actual performance, whereas in the uncontrollability condition, pre-determined random order false feedback was provided. Thus, in controllability conditions, the level of difficulty was known to participants, while in uncontrollability conditions, it remained unknown. In Study 2, in the course of IHT, no feedback at all was provided in either condition, so participants did not receive any information about the objective difficulty of the task, i.e., its solvability. In both studies, we measured NFC on a scale (Kossowska 2003).

In line with MIT, we predicted the main disengagement effect, i.e., that participants would show lower effort mobilization in the uncontrollability condition (in contrast to the controllability condition). In addition, we also expected that effort investment patterns (as measured by SBP) in these conditions would be moderated by NFC. Thus, we
Fig. 1 Predictions of effort investment in uncontrollability (vs. controllability condition), guding by the potential motivation (high-high NFC, and lowlow NFC)
Low NFC

\section{$\underline{\text { Uncontrollability condition }}$}

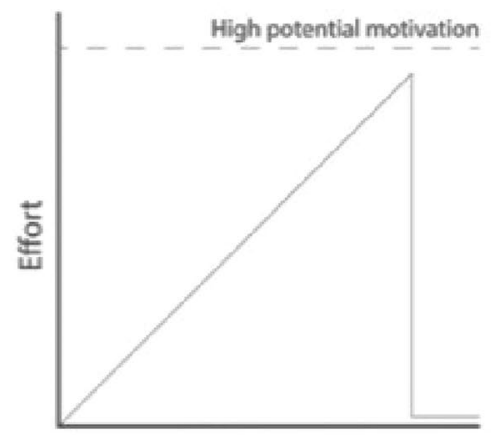

\section{Controllability condition}

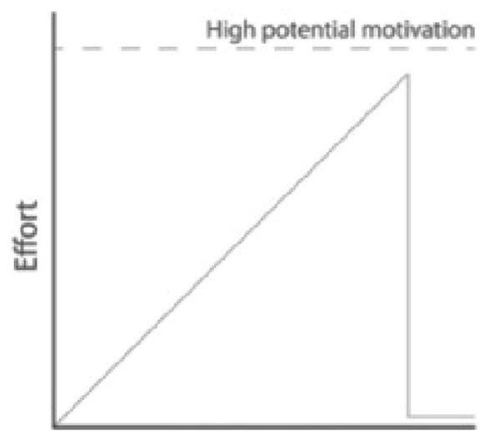


anticipated that individuals low in NFC would show an effort disengagement pattern (decreased SBP) when faced with uncontrollability i.e., participants would withhold their effort in the uncontrollability condition (vs. the controllability condition). In contrast, high NFC individuals would prolong their effort engagement because, in both the controllability and uncontrollability conditions, engagement should be equally justified for high NFC individuals. More specifically, although in the controllability condition, for both high and low NFC individuals, effort investment would be justified (high potential motivation), in the uncontrollability condition, only high-NFC people should be sufficiently motivated to persist in engaging effort, whereas low-NFC participants should not (low potential motivation).

\section{Study 1}

\section{Method}

\section{Participants}

Eighty-one participants, mostly undergraduate students, were asked to take part in the experiment; they received financial compensation of 20 PLN (approx. \$5). Data from three participants were excluded before the data analysis stage because of their low accuracy rates obtained in the controllability condition $(52,55$, and $57 \%$ of overall correct responses). The remaining sample of seventy-eight participants consisted of 47 females and 25 males $(\mathrm{M}$ age $=25.03$, $\mathrm{SD}=5.77)$. We ran an a priori power analysis $\left(\mathrm{G}^{*}\right.$ Power 3.1, Faul et al. 2009) with a small effect size of $f^{2}=0.10$ and power at 0.80 (Cohen 1988). This showed that a sample of 81 participants would be necessary for any moderation analysis in the multiple regression model $\left(\mathrm{R}^{2}\right.$ increase due to the addition of a single regression coefficient) to obtain the assumed power. We did not conduct any statistical analyses before completing the collection of data. All participants gave informed written consent before the experiment in accordance with the Institutional Review Board.

\section{Measures}

The need for closure (NFC) was measured at the beginning of the experiment with the long version of the Need for Cognitive Closure Scale (Webster and Kruglanski 1994; Polish version by Kossowska 2003). The scale consists of 33 items divided into five subscales: preference for order and structure, predictability of future contexts, affective discomfort occasioned by ambiguity, closed-mindedness, and decisiveness. Since the decisiveness subscale has been argued to be related to a different underlying process, and to also tap into the ability construct (Roets and van Hiel 2007), it was not included in further analyses. A global NFC score was calculated by averaging responses from all the items (Cronbach's $\alpha=0.84, \mathrm{M}=3.54, \mathrm{SD}=0.58$ ).

\section{Uncontrollability manipulation}

Uncontrollability was induced using a computerized version of the Behavioural Helplessness Training (BHT). The task used to evoke an experience of uncontrollability, developed by Kofta and Sedek (1989), was based on the original research on learned helplessness in humans (Hiroto and Seligman 1975). The task consisted of six concept-formation problems. For each problem, twelve screens with two stimulus patterns (figures) on each were presented to the participant. Each figure featured the following dimensions: (a) size (small or large), (b) shape (triangle or circle), (c) surface (plain or striped), (d) position of line (at the top or bottom of the figure), and (e) the size of the letter " $r$ " in the middle of the figure (lowercase or uppercase). In the uncontrollability condition, pairs of figures were shown sequentially, and participants were asked to select one from each pair of figures, indicating what they thought the solution to the problem was. They were instructed that, by paying attention to the feedback administered by the program ("right" or "wrong"), one could determine the correct feature of the figure. However, in the uncontrollability condition, the feedback was administered in a pre-determined random order, such that each participant was given 50\% "right" and 50\% "wrong" feedback on each problem. After the presentation of each problem, a list of ten features (solutions) was presented to the participants, and they were then asked to indicate the answer by pressing the corresponding key on the computer keyboard. The list of problems was identical as in uncontrollability conditions, however the feedback provided during the task always accurately informed the participants of their actual performance. Thus, in the controllability condition (as opposed to the uncontrollability one), it was possible for the participants to determine the diagnostic feature of the figure, and so correctly solve all the problems by paying attention to the feedback provided, and thus adjust their effort accordingly. In both conditions, the time available to make a decision was unlimited.

\section{Systolic blood pressure}

Effort was assessed by measuring SBP, which is a widely used and accepted index of sympathetic nervous system activation indicating effort investment (Gendolla and Silvestrini 2015; Light 1981; Wright 1996). To obtain cardiac response indices, change scores were computed for each participant by subtracting the baseline data average (during a relaxing, 8-min video before the task) from the mean of the measurement obtained during the task (Llabre et al. 1991). 
Table 1 Means and standard deviations (in parentheses) for cardiovascular measures (SBP, DBP and HR) taken under (un)controllability manipulations

\begin{tabular}{|c|c|c|c|c|c|c|}
\hline & \multicolumn{3}{|l|}{ Baseline } & \multicolumn{3}{|l|}{ Task } \\
\hline & $\mathrm{SBP}(\mathrm{mmHg})$ & $\mathrm{DBP}(\mathrm{mmHg})$ & $\mathrm{HR}(\mathrm{bpm})$ & $\mathrm{SBP}(\mathrm{mmHg})$ & $\mathrm{DBP}(\mathrm{mmHg})$ & $\mathrm{HR}(\mathrm{bpm})$ \\
\hline \multicolumn{7}{|l|}{ Study 1} \\
\hline Controllable condition & $122.82(17.68)$ & $73.55(12.41)$ & $80.67(8.67)$ & $126.73(20.58)$ & $75.68(14.05)$ & $81.69(9.01)$ \\
\hline Uncontrollable condition & $123.97(21.48)$ & $74.53(17.16)$ & $76.11(10.32)$ & $123.41(19.58)$ & $75.49(15.77)$ & $77.54(10.14)$ \\
\hline \multicolumn{7}{|l|}{ Study 2} \\
\hline Controllable condition & $126.73(10.21)$ & $79.05(5.65)$ & $80.61(4.05)$ & $133.64(11.19)$ & $82.29(13.44)$ & $81.91(6.44)$ \\
\hline Uncontrollable condition & $124.18(9.99)$ & $76.90(8.81)$ & $82.64(4.06)$ & $129.19(12.13)$ & $79.13(15.36)$ & $79.90(5.88)$ \\
\hline
\end{tabular}

We also collected diastolic blood pressure (DBP) and heart rate (HR), but did not analyze these as they are not reliable indexes of effort (Table 1).

\section{Procedure}

Participants upon arrival were asked to sign a consent form. On being seated in front of a computer screen, they were asked to fill in the NFC questionnaire, which was administered on-line. Next, they performed the concept formation task, which was the uncontrollability manipulation (Behavioral Helplessness Training; BHT, see Sedek and Kofta 1990). Participants were randomly assigned to one of two experimental conditions: uncontrollability or controllability. Finally, they were thanked and debriefed. The task, which was programmed in E-Prime version no. 2, was displayed on a 24-inch gaming monitor at a viewing distance of $50 \mathrm{~cm}$. Cardiovascular measurement was continuously taken throughout the whole task with beat-by-beat sampling. Systolic blood pressure (SBP) was assessed using the Finometer Midi Model-2 (Finapres Medical Systems, Amsterdam, the Netherlands), which measures finger arterial pressure using finger cuffs (Penaz 1973).

\section{Results and discussion}

\section{Baseline cardiovascular values}

First of all, we tested whether there were any effects stemming from baseline measures of NFC, conditions, or the interaction of both. This analysis was performed to ensure that we could calculate a reliable cardiovascular change index. We ran model 1 in the PROCESS macro (Hayes 2013). The experimental conditions were coded: $0-$ controllability, 1 -uncontrollability. We found no main effect of NFC $(b=2.03, \mathrm{SE}=6.44, t=0.31, p=0.7538,95 \% \mathrm{CI}$ $[-10.81 ; 14.87])$ nor of experimental conditions $(b=3.33$, $\mathrm{SE}=38.50, t=0.09, p=0.9313,95 \%$ CI $[-73.43 ; 80.09])$ on SBP values. Also, there was no significant interaction between the experimental conditions and NFC $(b=-0.65$, $\mathrm{SE}=9.94, t=-0.06, p=0.9485,95 \%$ CI $[-20.47 ; 19.18])$.

\section{Cardiovascular change}

We tested our main prediction that the level of NFC would moderate the effects of uncontrollability on invested effort: as with the baseline measures, we used the PROCESS macro
Fig. 2 Differences in effort investment (indexed with SBP) depending on condition for high and low NFC individuals separately (Study 1)

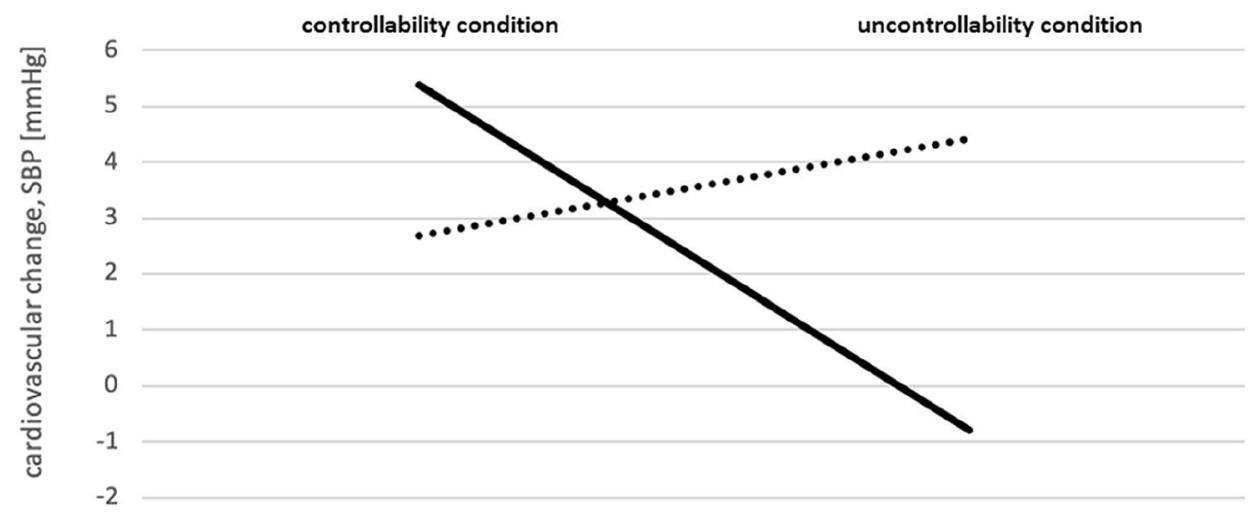

LNFC $\quad \ldots . .$. HNFC 
(Hayes 2013, model 1). The experimental conditions again were coded: 0 -controllability, $1-$ uncontrollability, and this variable served as a predictor in the tested model. We used a continuous measure of NFC as the moderator, and we used systolic blood pressure as the dependent variable. We found a weak main effect of uncontrollability on SBP $(b=-34.29, \mathrm{SE}=17.39, t=-1.97, p=0.0524,95 \% \mathrm{CI}$ $[-68.94 ; 0.36])$. There was no significant relation between NFC and SBP alone $(b=-2.87, \mathrm{SE}=2.85, t=-1.01$, $p=0.3166,95 \%$ CI $[-8.54 ; 2.80])$. Additionally, there was a marginally significant interaction between the experimental conditions and NFC $(b=8.39, \mathrm{SE}=4.51, t=1.86$, $p=0.0668,95 \%$ CI $[-0.60 ; 17.38])$. Simple slope conditional analysis revealed that low-NFC participants invested less effort in the uncontrollability condition in comparison to the controllability one $(b=-6.19, \mathrm{SE}=3.00, t=-2.06$, $p=0.0426,95 \%$ CI $[-12.17 ;-0.21])$. The slope for highNFC individuals remained positive and nonsignificant, $(b=1.75, \mathrm{SE}=2.96, t=0.59, p=0.5558,95 \%$ CI $[-4.14$; $7.64]$ ), revealing that there were no differences between the uncontrollability and controllability conditions for them. All of the above results can be seen in Fig. 2 .

Consistent with the predictions, we obtained the main effect of withholding effort by participants when the uncontrollability condition prevailed in comparison to when conditions were controllable. Importantly, low-NFC individuals followed this pattern, whereas high-NFC participants did not. However, the interaction effect obtained was statistically weak, which may have been due to the exclusion of participants with low accuracy from the initial sample size; therefore, the study might be underpowered. It is also probable that the type of applied uncontrollability manipulation was too weak, in the sense that by receiving feedback, the participants' level of experienced uncertainty was low. Given all of this, we decided to run another study using a manipulation that more directly affects the uncertainty-related aspect of uncontrollability (Bukowski et al. 2015). This manipulation involves zero feedback being provided to any of the participants, which additionally increases the level of uncertainty regarding the solvability of the performed tasks. Moreover, a manipulation of this sort should be more suited to our research goal i.e., when task difficulty is unknown, effort should be proportional only to the importance of success (for an overview, see: Gendolla et al. 2012). Additionally, we decided to pre-select a sample of low- and high-NFC participants to ensure that we addressed people differing in motivational characteristics, as well as to achieve the required statistical power.

\section{Study 2}

\section{Method}

\section{Participants}

Forty-five volunteers took part in the experiment; they each received financial compensation of 20 PLN. The sample contained 27 females and 18 males $(\mathrm{M}$ age $=24.29, \mathrm{SD}=3.57$ ). All participants gave informed written consent before the experiment, in accordance with the Institutional Review Board. Before the experiment, a group of 295 students (242 women, 53 men; mean age $=25.91, \mathrm{SD}=6.59$ ) filled out the NFC Scale (Webster and Kruglanski 1994; Kossowska et al. 2003). The NFC scores were then used to create two groups, one with higher ( $>90$ th percentile) and one with lower $(<10$ th percentile) NFC. Our decision to increase the statistical power of the study by using a pre-selected sample of participants (EGA, Extreme Group Approach) who were either very high or very low in the crucial variable, was based on a suggestion from Preacher et al. (2005). Thus, when running an a priori power analysis $\left(\mathrm{G}^{*}\right.$ Power 3.1, Faul et al. 2009), we assumed a larger effect size than in Study 1: $f^{2}=0.20$ and power at 0.80 (Cohen 1988). This showed that a sample of 42 participants would be necessary for moderation analysis in the multiple regression model $\left(\mathrm{R}^{2}\right.$ increase due to adding a single regression coefficient) in order to obtain the assumed power. We did not conduct any statistical analyses before we finished collecting the data. All participants gave informed written consent before the experiment, in accordance with the Institutional Review Board.

\section{Measures}

Need for closure (NFC) was measured at the beginning of the experiment with the long version of the Need for Cognitive Closure Scale, identical to the one used in Study 1 (Cronbach's $\alpha=0.82, \mathrm{M}=3.44, \mathrm{SD}=0.70$ ). The NFC scores were used to create two groups with higher ( $>90$ th percentile) and lower $(<10$ th percentile) NFC scores.

\section{Uncontrollability manipulation}

Informational Helplessness Training (IHT) was used to induce an experience of uncontrollability. The procedure was based on the original manipulation, as previously developed, and described by Sedek and Kofta (1990). This procedure has been reliably shown to evoke a sense of uncontrollability and irreducible uncertainty (Kofta and Sedek 1999). The procedure consisted of six discrimination (concept-formation) problems with twelve trials for each problem. In each trial, participants were presented with one figure on the 
screen with a fixed presentation time of $5000 \mathrm{~ms}$. Figures could vary on five dimensions: (a) size (small or large), (b) shape (triangle or circle), (c) surface (plain or striped), and (d) the position of a line (at the top or bottom of the figure), and (e) the lettercase of the letter ' $r / R$ ' in the middle of a figure (lowercase ' $r$ ' or uppercase ' $R$ '). Participants were told that by using information displayed during each trial (i.e., 'yes' or 'no' accompanying the figure presented on the screen) they could resolve the problem, that is, identify the target feature of the figures. It was explained that 'yes' indicates the presence of (e.g., the figure is a lowercase, striped triangle), and 'no' indicates the absence of the target feature in the figure (e.g., the figure is a small, stripped circle). After being exposed to the twelve figures, each participant was given a full list of the possible solutions and was asked to select one. All participants were informed that all the tasks were solvable. The task was explained and demonstrated on an example, which was solvable. The actual manipulation began after a solvable practice trial and having ensured that participants understood the nature of the task.

In the uncontrollability condition, participants were asked to perform six unsolvable discrimination problems (i.e., the sequence of 'yes' and 'no' indications regarding the presence of the target feature was arranged in such a way that each possible hypothesis of a problem solution received $50 \%$ confirmatory and 50\% disconfirmatory evidence). Thus, in reality, it was not possible to solve any of the tasks. Importantly, the participants were provided with zero feedback regarding the correctness of their choices of the six target features.

In the controllability condition, participants performed six solvable discrimination problems (i.e., by using the 'yes' and 'no' information presented with each figure, it was actually possible to reach the correct solution). As was the case in the uncontrollability condition, participants in the controllability condition were also provided with zero feedback regarding their performance. This lack of feedback for in both conditions is a specific characteristic of the informational helplessness induction procedure, which was developed to examine the impact of irreducible uncertainty related to uncontrollable events on task performance (Kofta and Sedek 1999).

\section{Manipulation check}

Three questions measured perceptions of certainty, difficulty, and control after the manipulation to assess its efficiency (How certain are you that you were accurate when doing the tasks? How difficult did you find the tasks? To what extent did you feel that you had control over your performance?). Participants answered using a 7-point scale (e.g., from 1absolutely no control, to 7-full control).

\section{Systolic blood pressure}

As in Study 1, effort was assessed by measuring SBP. To obtain cardiac response indices, change scores were computed for each participant by subtracting the baseline data average (taken during a relaxing, 8-min video before the task) from the mean of measurement from the task. We also collected diastolic blood pressure (DBP) and heart rate (HR) but did not analyse them as they are not reliable indexes of effort.

\section{Procedure}

Participants upon arrival were asked to sign the consent form. They were then seated in front of a computer screen and asked to perform a concept formation task: the (un)controllability manipulation (Informational Helplessness Training; IHT). Participants were randomly assigned to one of two experimental conditions, every two participants (selecting at random within the same NFC level group, whether high or low) were randomly assigned to either the uncontrollability or controllability condition. Having completed the IHT task, participants were asked a set of questions regarding the efficiency of the manipulation (manipulation check); then they were thanked and debriefed. The experiment was conducted in the same laboratory as Study 1, so all the technical aspects were identical to those in Study 1, such as the software used for procedures and the equipment used to harvest cardiovascular data.

\section{Results and discussion}

\section{Manipulation checks}

To check the effectiveness of the uncontrollability manipulation, we compared the conditions using Univariate ANOVA tests. In the uncontrollability condition (vs. controllability), we found significantly lower scores for perceived control in the uncontrollability vs controllability condition: $M_{\text {uncontrollability }}=1.78, S D_{\text {uncontrollability }}=0.85$ vs. $\quad \mathrm{M}_{\text {controllability }}=5.63, \quad \mathrm{SD}_{\text {controllability }}=1.21$, $F(1,45)=157.51, p<0.0001, \eta^{2}=0.420$, and for perceived certainty of being correct when performing the tasks: $\mathrm{M}_{\text {uncontrollability }}=1.74, \mathrm{SD}_{\text {uncontrollability }}=1.21$ vs. $\quad \mathrm{M}_{\text {controllability }}=5.58, \quad \mathrm{SD}_{\text {controllability }}=1.10$, $F(1,45)=173.56, p<0.0001, \eta^{2}=0.419$. Participants in the uncontrollability condition scored higher on the item that assessed the perceived difficulty of the tasks: $\mathrm{M}_{\text {uncontrollability }}=5.13, \mathrm{SD}_{\text {uncontrollability }}=1.63$, $\mathrm{M}_{\text {controllability }}=2.79, \mathrm{SD}_{\text {controllability }}=1.74, F(1,45)=22.49$, 
$p<0.001, \eta^{2}=0.174$. The results proved the efficiency of the manipulations.

\section{Baseline cardiovascular values}

First, we tested whether there were any effects of NFC, condition, or the interaction of both on a baseline measure. This analysis was performed to ensure that we could calculate a reliable cardiovascular change index. We ran model 1 in the PROCESS macro (Hayes 2013). The experimental conditions were coded: 0 -controllability, 1 - uncontrollability condition. We found no main effect of NFC $(b=20.04$, $\mathrm{SE}=19.61, t=1.02, p=0.3335,95 \% \mathrm{CI}[-24.34 ; 64.42])$ nor of condition $(b=10.16, \mathrm{SE}=7.28, t=1.39, p=0.1967$, $95 \%$ CI $[-6.33 ; 26.64])$ on the raw SBP value. Also, there was no significant interaction between the experimental conditions and NFC $(b=-8.68, \mathrm{SE}=11.66, t=-0.74$, $p=0.4759,95 \%$ CI $[-35.06 ; 17.71])$.

\section{Cardiovascular change}

To test our main prediction that the level of need for closure would moderate the effects of uncontrollability on the invested effort, we used the PROCESS macro (Hayes 2013, model 1) again. The experimental conditions were again coded: 0 -controllability, 1 - uncontrollability condition; this variable served as a predictor in the tested model. We used NFC as the moderator and systolic blood pressure as the dependent variable.

We found a significant main effect of condition on SBP $(b=-7.67, \mathrm{SE}=3.31, t=-2.31, p=0.0256,95 \%$
CI $[-14.35 ;-0.98])$, showing that participants withheld their effort investment in the uncontrollability condition. There was also a significant and negative relation solely between NFC and SBP $(b=-17.90, \mathrm{SE}=7.80, t=-2.29$, $p=0.0269,95 \%$ CI $[-33.64 ;-2.15])$. Importantly, there was a significant interaction between the experimental condition and NFC $(b=12.40, \mathrm{SE}=4.84, t=2.56, p=0.0142$, $95 \%$ CI $[2.62 ; 22.17])$, revealing that participants with low NFC withdrew their effort more in the uncontrollability condition than in the controllability condition $(b=-7.67$, $\mathrm{SE}=3.31, t=-2.31, p=0.0256,95 \%$ CI $[-14.35 ;-0.98])$. The slope for high-NFC individuals remained positive but nonsignificant $(b=4.73, \mathrm{SE}=3.53, t=1.33, p=0.1879,95 \%$ CI $[-2.40 ; 11.86])$. All of the above results are shown in Fig. 3.

The results presented replicate the findings of Study 1, providing support for the hypothesis regarding the moderating impact of NFC on effort investment. More specifically, we observed a decreased effort-mobilization pattern that was manifested in decreased SBP among low- but not high-NFC individuals in the uncontrollability condition as compared to the controllability one. This means that low-NFC individuals disengage from the task since resolving ambiguous situations is less of a focal goal for them. High-NFC individuals, however, are sufficiently motivated to persevere in the engagement of effort in such circumstances.

\section{General discussion}

In these studies, we addressed the role of the Need for Closure as a moderator of the disengagement effect when experiencing uncontrollability. We assumed that NFC would modulate the level of potential motivation, and thus shape the effort investment pattern detected when difficulty is
Fig. 3 Differences in effort investment (indexed with SBP) depending on condition for high and low NFC individuals separately (Study 2)

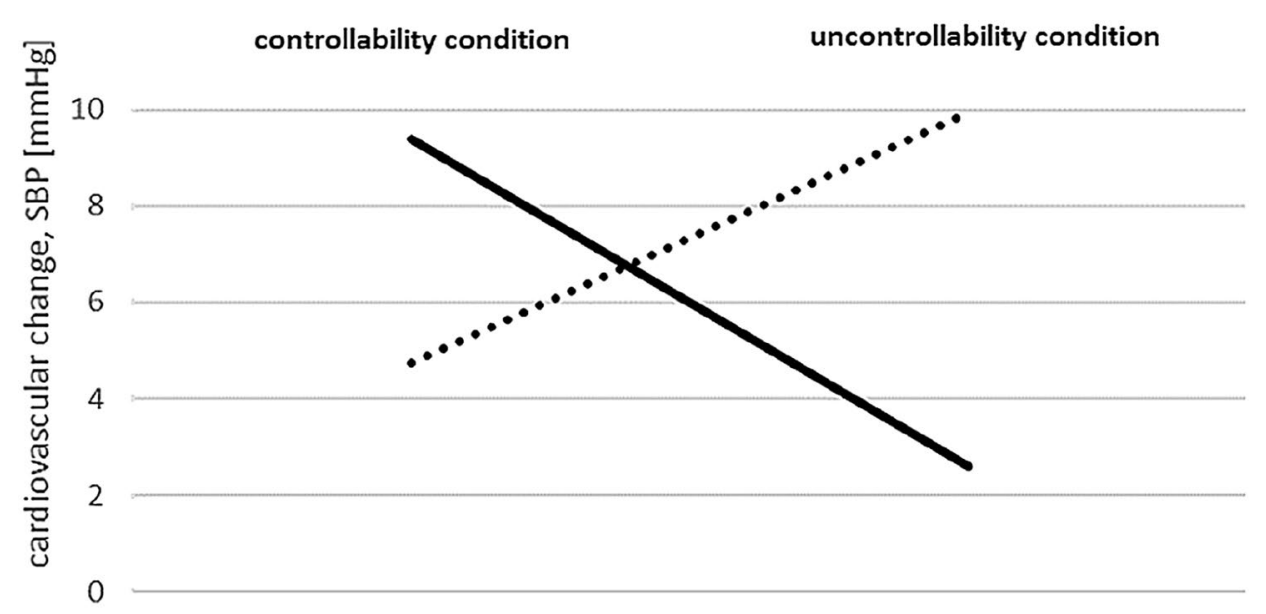

LNFC $\cdots \ldots$ HNFC 
unknown. In fact, we were able to observe this main effect of uncontrollability on effort, as measured with SBP, i.e., all the participants withheld their engagement in uncontrollable situations as compared to controllable situations. This result replicates a very large number of previous findings (Bukowski et al. 2015; Kofta and Sedek 1998; Lefcourt 1976, 1980). Moreover, in line with our expectations, in the first study, we found an interaction between NFC and effort response to un(controllability), albeit a weak one. Specifically, low-NFC individuals disengaged from the task (decreased SBP) in the uncontrollability condition, whereas their high-HFC counterparts, those with a high level of motivation to reduce uncertainty, continued to invest effort in the given experimental settings. We argue that this stems from the fact that, among low-NFC individuals, a low degree of importance is attached to gaining certainty, leading to a low potential motivation to invest effort. It is plausible that, if the task context were to make it clear that the concept formation problems are unsolvable, for example, by providing participants with actual feedback on their performance, then high NFC individuals would most probably also withhold their efforts. Still, it is precisely the uncertainty factor that seems to motivate those who score high in NFC to prolong their effort investment in the task, whereas this is not the case for their low-NFC counterparts. The results obtained are in line with some previous findings showing that, while the effort investment of low-NFC individuals is affected only by the objective difficulty of the task, those with highNFC are driven more by the outcome relevance case i.e., the goal of gaining certainty; in other words, achieving closure (Viola et al. 2015). In a task performance situation, closure is equivalent to attaining certainty that the task requirements (the goal presented in the task instructions) have been or will be met (e.g., Chiu et al. 2000; Szumowska and Kossowska 2017).

An alternative explanation of the findings could be that those with high NFC perceived the task situation as not as uncontrollable and hopeless as their counterparts, rather than perceiving it in terms of the level of behavioural challenge posed (Wright 1996). This interpretation is in line with the Motivational Readiness Theory by Kruglanski et al. (2014), which states that the willingness or inclination to act in the service of a desire is determined by two factors: the Want state, and the Expectancy of being able to satisfy it. These factors, however, are not independent because when people want something very much, they consider it more achievable and likely (Kruglanski et al. 2014).

Importantly, these results show what Ford and Brehm (1987) postulated: that when examining motivational phenomena that are as complex as the experience of uncontrollability, it is crucial to test not only one type of factor, i.e., the motivation induced by the experimental settings, but also individual human chronic motives. In previous studies on the motivational consequences of uncontrollability, researchers focused predominantly on the solvability aspect of tasks; hence, it was claimed that people tend to disengage when they face unsolvable situations (Kofta 1993; von Hecker and Sedek 1999). By including the chronic motivation to reduce uncertainty as a factor, we showed that certain individuals maintain their investment of effort in uncontrollable situations, even if it is objectively unjustified.

The findings we obtained also supplement the existing research examining the impact of NFC on various physiological measures (e.g., Kossowska et al. 2019; Szumowska et al. 2017; Sankaran et al. 2017). Furthermore, our research extends the results described by Richter et al. (2012), who found that NFC moderates the impact of task difficulty on engagement-related myocardial sympathetic responses. Specifically, when task difficulty was high, PEP reactivity was also elevated for high NFC participants. Our findings reveal a similar pattern with respect to the moderating role of NFC on effort investment, indexed in our studies by the SBP measure. A notable difference between the Richter et al. (2012) study and ours is that the current findings show that what impacts effort investment besides task difficulty, and focus one the role of uncertainty about how to exercise control over a task. Also, the reaction to this uncertainty varies between people who differ in their chronic motivation to achieve cognitive closure. The results reveal certain motivational pre-conditions that diminish the tendency to disengage from effortful activity when faced with uncontrollable situations, in which the level of uncertainty is extremely high; the results thereby supplement previous findings on effort investment in such cases (Bukowski et al. 2015; Kofta and Sedek 1998; Lefcourt 1976, 1980). On a more general note, our research parallels those showing that the energy conservation principle has a number of important boundary conditions.

A further aspect of this research worth highlighting is that being high in NFC can also carry some potentially adverse implications. The primary motivational mechanism that accounts for people's tendency to disengage with unsolvable situations is known as the resource conservation principle (Brehm and Self 1989). In other words, there is no point in wasting resources when there is no chance of achieving a positive outcome in a given case. This mechanism prevents us from unnecessary exhaustion, so the investment pattern that high-NFC individuals display in situations in which there is no right solution to a problem, and therefore no necessity to invest more effort could be deemed dysfunctional. Indeed, this could indicate a certain form of cognitive and motivational rigidity. This observation could be valuable in the field of clinical psychology since individual differences in uncertainty tolerance can shape the treatment process of major depressive disorders. This is especially of relevance, due to the fact that a failure in goal disengagement, 
when it is objectively justified by the insolvability within the context (unattainable goals), is associated with higher levels of depressive symptomatology, higher degrees of stress, and increased levels of emotional upset (Wrosch et al. 2007).

A potential weakness of the research presented here might be the effort index used. Systolic Blood Pressure is not an ideal indicator of motivational effort from a biological standpoint as it is not only driven by the sympathetic nervous system activity, but is also influenced by total peripheral resistance, which is sometimes modulated by the parasympathetic system. However, SBP is still strongly influenced by the force of heart contractions (Wright 1996). Moreover, SBP is commonly used as an indication of effort in a large body of research showing that it responds well to the changes in task difficulty or success importance (see Gendolla et al. 2012; Wright and Kirby 2001, for overviews). Lastly, a possible limitation of this research comes from the under-powered sample size in Experiment 1.

To conclude, the results we obtained show that there are dynamic and individually related differences in effort investment patterns when experiencing uncontrollability conditions. Further research is needed to address the more general question concerning the dispositional and situational conditions which motivate people to exert mental effort in circumstances that evoke high uncertainty and are beyond one's personal control.

Author contributions MK developed the overall framework of the studies, and PS contributed to the data collection and performed the data analyses. All authors jointly contributed to: the concept and design of the studies, the preparation of the manuscript, and the approval of the final version of the manuscript for submission.

Funding This study was supported by National Science Center (Grant No. DEC 2011/02/A/HS6/00155).

Open Access This article is licensed under a Creative Commons Attribution 4.0 International License, which permits use, sharing, adaptation, distribution and reproduction in any medium or format, as long as you give appropriate credit to the original author(s) and the source, provide a link to the Creative Commons licence, and indicate if changes were made. The images or other third party material in this article are included in the article's Creative Commons licence, unless indicated otherwise in a credit line to the material. If material is not included in the article's Creative Commons licence and your intended use is not permitted by statutory regulation or exceeds the permitted use, you will need to obtain permission directly from the copyright holder. To view a copy of this licence, visit http://creativecommons.org/licenses/by/4.0/.

\section{References}

Brehm, J. W., \& Self, E. A. (1989). The intensity of motivation. Annual Review of Psychology, 40, 109-131. https://doi.org/10.1146/annur ev.ps.40.020189.000545.
Bukowski, M., Asanowicz, D., Marzecová, A., \& Lupiáñez, J. (2015). Limits of control: The effects of uncontrollability experiences on the efficiency of attentional control. Acta Psychologica, 154, 43-53. https://doi.org/10.1016/j.actpsy.2014.11.005.

Bukowski, M., \& Kofta, M. (2017). From coping to helplessness: Effects of control deprivation on cognitive and affective processes. In M. Bukowski, I. Fritsche, A. Guinote, \& M. Kofta (Eds.), Coping with lack of control in a social world (pp. 15-34). New York: Routledge.

Burger, J. M. (1989). Negative reactions to increases in perceived personal control. Journal of Personality and Social Psychology, 56(2), 246-256. https://doi.org/10.1037/0022-3514.56.2.246.

Cohen, J. (1988). Statistical power analysis for the behavioral sciences (2nd ed.). Hillsdale, NJ: Erl-baum.

Faul, F., Erdfelder, E., Buchner, A., \& Lang, A. G. (2009). Statistical power analyses using $G^{*}$ Power 3.1: Tests for correlation and regression analyses. Behavior Research Methods, 41(4), 1149-1160.

Ford, C. E., \& Brehm, J. W. (1987). Effort expenditure following failure. In Coping with negative life events (pp. 81-103). Boston, MA: Springer.

Gendolla, G. H., \& Silvestrini, N. (2015). Bounded effort automaticity: A drama in four parts. In Handbook of biobehavioral approaches to self-regulation (pp. 271-286). Springer, New York, NY.

Gendolla, G. H. E., \& Wright, R. A. (2005). Motivation in social settings: studies of effort-related cardiovascular arousal. In J. P. Forgas, K. Williams, \& W. von Hippel (Eds.), Social motivation (pp. 71-90). New York: Cambridge University Press.

Gendolla, G. H., Wright, R. A., \& Richter, M. (2012). Effort intensity: Some insights from the cardiovascular system. In R. M. Ryan (Ed.), The Oxford handbook of human motivation (pp. 420-438). Oxford: Oxford University Press.

Hayes, A. F. (2013). Methodology in the social sciences. Introduction to mediation, moderation, and conditional process analysis: A regression-based approach. New York, NY: Guilford Press.

Hiroto, D. S., \& Seligman, M. E. (1975). Generality of learned helplessness in man. Journal of Personality and Social Psychology, 31(2), 311-327. https://doi.org/10.1037/h0076270.

Kofta, M. (1993). Uncertainty, mental models, and learned helplessness: An anatomy of control loss. In G. Weary, F. Gleicher, \& K. L. Marsh (Eds.), Control motivation and social cognition. New York, NY: Springer. https://doi.org/10.1007/978-1-4613-8309-3_5.

Kofta, M., \& Sedek, G. (1998). Uncontrollability as a source of cognitive exhaustion. In M. Kofta, G. Weary, \& G. Sedek (Eds.), Personal control in action the springer series in social clinical psychology. Boston, MA: Springer. https://doi. org/10.1007/978-1-4757-2901-6_16.

Kofta, M., \& Sedek, G. (1999). Uncontrollability as irreducible uncertainty. European Journal of Social Psychology, 29(5-6), 577-590.

Kossowska, M. (2003). Różnice indywidualne w potrzebie poznawczego domknięcia. Przeglad Psychologiczny, 46(4), 355-374.

Kossowska, M., Szumowska, E., Dragon, P., Jaśko, K., \& Kruglanski, A. W. (2018). Disparate roads to certainty processing strategy choices under need for closure. European Review of Social Psychology, 29(1), 161-211.

Kossowska, M., Szwed, P., \& Wyczesany, M. (2019). Motivational effects on brain activity: Need for closure moderates the impact of task uncertainty on engagement-related P3b. NeuroReport, 30(17), 1179-1183.

Kruglanski, A. W. (1989). The psychology of being "right": The problem of accuracy in social perception and cognition. Psychological Bulletin, 106(3), 395-409. https://doi. org/10.1037/0033-2909.106.3.395. 
Kruglanski, A. W., Chernikova, M., Rosenzweig, E., \& Kopetz, C. (2014). On motivational readiness. Psychological Review, 121(3), 367-388. https://doi.org/10.1037/a0037013.

Kruglanski, A. W., \& Webster, D. M. (1996). Motivated closing of the mind: "Seizing" and "freezing." Psychological Review, 103(2), 263-283. https://doi.org/10.1037/0033-295X.103.2.263.

Langer, E. J., \& Roth, J. (1975). Heads I win, tails it's chance: The illusion of control as a function of the sequence of outcomes in a purely chance task. Journal of Personality and Social Psychology, 32(6), 951-955.

Lefcourt, H. M. (1976). Locus of control and the response to aversive events. Canadian Psychological Review/Psychologie Canadienne, 17(3), 202-209. https://doi.org/10.1037/h0081839.

Lefcourt, H. M. (1980). Locus of control and coping with life's events. In E. Staub (Ed.), Personality: Basic aspects and current research (pp. 200-235). Englewood Cliffs, NJ: Prentice-Hall.

Light, K. C. (1981). Cardiovascular responses to effortful active coping: Implications for the role of stress in hypertension development. Psychophysiology, 18(3), 216-225.

Llabre, M. M., Spitzer, S. B., Saab, P. G., Ironson, G. H., \& Schneiderman, N. (1991). The reliability and specificity of delta versus residualized change as measures of cardiovascular reactivity to behavioral challenges. Psychophysiology, 28(6), 701-711.

Maier, S. F., \& Seligman, M. E. (1976). Learned helplessness: Theory and evidence. Journal of Experimental Psychology, 105(1), 3-46. https://doi.org/10.1037/0096-3445.105.1.3.

Mikulincer, M. (1994). The Plenum series in social/clinical psychology. Human learned helplessness: A coping perspective. New York, NY: Plenum Press. https://doi.org/10.1007/978-1-4899-0936-7.

Penaz, J. (1973). Photoelectric measurement of blood pressure, volume and flow in the finger. In Digest of the 10th international conference on medical and biological engineering, Dresden (p. 104).

Pittman, T. S., \& Pittman, N. L. (1980). Deprivation of control and the attribution process. Journal of Personality and Social Psychology, 39(3), 377-389. https://doi.org/10.1037/0022-3514.39.3.377.

Preacher, K. J., Rucker, D. D., MacCallum, R. C., \& Nicewander, W. A. (2005). Use of the extreme groups approach: A critical reexamination and new recommendations. Psychological Methods, 10, 178-192. https://doi.org/10.1037/1082-989X.10.2.178.

Richter, M., Baeriswyl, E., \& Roets, A. (2012). Personality effects on cardiovascular reactivity: Need for closure moderates the impact of task difficulty on engagement-related myocardial beta-adrenergic activity. Psychophysiology, 49(5), 704-707.

Richter, M., Brinkmann, K., \& Carbajal, I. (2016a). Effort and autonomic activity: A meta-analysis of four decades of research on motivational intensity theory. International Journal of Psychophysiology, 108, 34. https://doi.org/10.1016/j.ijpsy cho.2016.07.113.

Richter, M., Friedrich, A., \& Gendolla, G. H. (2008). Task difficulty effects on cardiac activity. Psychophysiology, 45(5), 869-875. https://doi.org/10.1111/j.1469-8986.2008.00688.x.

Richter, M., Gendolla, G. H., \& Wright, R. A. (2016b). Three decades of research on motivational intensity theory: What we have learned about effort and what we still don't know. In A. Elliot (Ed.), Advances in motivation science (Vol. 3, pp. 149-186). San Diego, CA: Elsevier.

Roets, A., Kruglanski, A. W., Kossowska, M., Pierro, A., \& Hong, Y, Y. (2015). The motivated gatekeeper of our minds: New directions in need for closure theory and research. In L. Berkowitz
(Ed.), Advances in experimental social psychology (Vol. 52, pp. 221-283). New York, NY: Academic Press.

Sankaran, S., Szumowska, E., \& Kossowska, M. (2017). When the going gets tough, the tough get going: Motivation towards closure and effort investment in the performance of cognitive tasks. Motivation and Emotion, 41(3), 308-321.

Sedek, G., \& Kofta, M. (1990). When cognitive exertion does not yield cognitive gain: Toward an informational explanation of learned helplessness. Journal of Personality and Social Psychology, 58(4), 729-743. https://doi.org/10.1037/0022-3514.58.4.729.

Seligman, M. E. P. (1975). A series of books in psychology. Helplessness: On depression, development, and death. New York, NY: W H Freeman.

Silvestrini, N., \& Gendolla, G. H. (2019). Affect and cognitive control: Insights from research on effort mobilization. International Journal of Psychophysiology, 143, 116-125.

Skinner, E. A. (1995). Perceived control, motivation, and coping (Vol. 8). Thousand Oaks, CA: Sage.

Szumowska, E., Szwed, P., Kossowska, M., \& Wright, R. (2017). Multifaceted effects of need for cognitive closure on effort: A cardiovascular response study. Motivation Science, 3(4), 369-382. https ://doi.org/10.1037/mot0000053.

Viola, V., Tosoni, A., Brizi, A., Salvato, I., Kruglanski, A. W., Galati, G., \& Mannetti, L. (2015). Need for cognitive closure modulates how perceptual decisions are affected by task difficulty and outcome relevance. PLOS ONE, 10(12), e0146002.

von Hecker, U., \& Sedek, G. (1999). Uncontrollability, depression, and the construction of mental models. Journal of Personality and Social Psychology, 77(4), 833-850. https://doi. org/10.1037/0022-3514.77.4.833.

Weary, G., Marsh, K. L., Gleicher, F., \& Edwards, J. A. (1993). Depression, control motivation, and the processing of information about others. In G. Weary, F. Gleicher, \& K. L. Marsh (Eds.), Control motivation and social cognition (pp. 255-287). New York, NY: Springer.

Webster, D. M., \& Kruglanski, A. W. (1994). Individual differences in need for cognitive closure. Journal of Personality and Social Psychology, 67(6), 1049-1062. https://doi. org/10.1037/0022-3514.67.6.1049.

Wright, R. A. (1996). Brehm's theory of motivation as a model of effort and cardiovascular response. In P. M. Gollwitzer \& J. A. Bargh (Eds.), The psychology of action: Linking cognition and motivation to behavior (pp. 424-453). New York, NY, US: Guilford Press.

Wright, R. A., \& Brehm, J. W. (1984). The impact of task difficulty upon perceptions of arousal and goal attractiveness in an avoidance paradigm. Motivation and emotion, 8(2), 171-181.

Wright, R. A., \& Kirby, L. D. (2001). Effort determination of cardiovascular response: An integrative analysis with applications in social psychology. In M. P. Zanna (Ed.), Advances in experimental social psychology (Vol. 33, pp. 255-307). New York, NY: Academic Press.

Wrosch, C., Miller, G. E., Scheier, M. F., \& De Pontet, S. B. (2007). Giving up on unattainable goals: Benefits for health? Personality and Social Psychology Bulletin, 33(2), 251-265.

Publisher's Note Springer Nature remains neutral with regard to jurisdictional claims in published maps and institutional affiliations. 